\title{
When COVID-19 Hits Tuberculosis: Unusual Association
}

\author{
Achrane J*, Bouyste K, Azzedine R, Daoudi M, Rhanim A, Achachi L, Herrak L, Elftouh M
}

Department of Pneumology and Phthisiology, Moulay Youssef hospital, Ibn Sina UHC, Faculty of Medicine and Pharmacy, Mohamed V University, Rabat, Morocco

DOI: $10.36347 /$ sasjm.2020.v06i09.002

| Received: 28.08.2020 | Accepted: 05.09.2020 | Published: 09.09.2020

*Corresponding author: $\mathrm{J}$. Achrane

Abstract

Case Report

Introduction: COVID-19 is a multi-organ disease secondary to SARS-Cov-2 this infection may be responsible in some cases for severe acute respiratory syndrome. The clinical characteristics and management of patients with pulmonary tuberculosis (TB). with COVID-19 are not yet clear and have not been sufficiently studied. Patient and method: In this observation, we report a case of SARS-Cov-2 infection revealing pulmonary tuberculosis, our management experience and the clinical and evolutionary data of this case. Results: This is a 20-year-old patient with pulmonary tuberculosis and COVID-19 co-infection held in front of an evocative clinical radio panel, positive COVID-19 PCR test and GeneXpert in sputum also positive. The thoracic CT showed an extended frosted glass appearance $(25 \%-50 \%)$ with multiple parenchymal condensations in favor of a CORADS 5, with presence of multiple nodular opacities sometimes excavated. The patient is put on protocol: Hydroxychloroquine + Azithromycin sulfate, associated with antibacillary treatment. The clinical evolution was marked by apyrexia at the end of the 3rd day of treatment with progressive improvement of his respiratory symptomatology. Conclusion: With the rapid spread of the COVID-19 pandemic, broader studies are needed to study the prognosis of tuberculosis -COVID-19.

Keywords: COVID-19, SARS-Cov-2, Tuberculosis, Tuberculosis Co-infection -COVID-19.

Copyright @ 2020: This is an open-access article distributed under the terms of the Creative Commons Attribution license which permits unrestricted use, distribution, and reproduction in any medium for non-commercial use (NonCommercial, or CC-BY-NC) provided the original author and source are credited.

\section{INTRODUCTION}

In December 2019, the discovery of several cases of unexplained severe lung disease in Hubei Province, China, resulted in the identification, in January 2020, of a new coronavirus, called SARS-CoV2 [2] responsible for COVID-19 disease. The rapid spread of this virus has led to a pandemic as early as March 2020, according to the World Health Organization (WHO) [3]. As for Morocco, the first case of COVID-19 was reported on March 04, 2020.

Tuberculosis and COVID19 are both respiratory diseases that affect the entire population, particularly the most vulnerable groups, and the prognosis of this association has not yet been studied.

We will share our experience in managing a case of simultaneous co-infection of SARS-CoV-2 and mycobacterium tuberculosis (TB), admitted to ibn Sina University Hospital in Rabat on April 6, 2020.

\section{OBSERVATION}

This is a 20-year-old patient with no toxic habits or history, having 10 days of admission with a confirmed family member with COVID-19. Who had been complaining for 20 days of a productive cough bringing back muco-purulent expectorations and stage 3 exercise dyspnea of $\mathrm{mMRC}$, complicated of chest pain, headache, anosmia, agueusie and diffuse polyathralgia for 03 days, evolving in a context of general state impairment and unencrypted fever? Clinical examination found a conscious patient febrile at $38.7^{\circ}$, polypneic resting with a $\mathrm{SaO} 2=93 \%$ in ambient air, blood pressure was 10/6 $\mathrm{mmHg}$, 95-beat/min tachycardia with snoring rails and left basal condensation syndrome on pleuro-pulmonary examination. A thoracic CT showed an extended frosted glass appearance (25\%-50\%) with multiple parenchymal condensations in favor of a CORADS 5, with presence of multiple nodular opacities sometimes excavated (image 1: a,b,c). In front of this clinical radio table a COVID-19 PCR test is performed confirming the detection of SARS-Cov-2 by multiplex real-time PCR/ CFX-96 biorad/ ABI 7500 Applied biosytem on a naso-pharyngeal sample. A geneXpert in the sputum is also requested returning positive, confirming pulmonary tubercolosis and COVID-19 co-infection. The biological assessment revealed a lymphopenia $780 / \mu 1$, a moderate inflammatory syndrome, while renal function, liver, as well as the blood ionogram were 
without particularities (Table 1), the electrocardiogram did not show any heart problems. The d-dimer rate was high at $8000 \mu \mathrm{g} / \mathrm{ml}$, a thoracic angio-scanner is performed, eliminating a proximal pulmonary embolism. Therefore, our patient was under COVID-19 protocol adopted by the Moroccan Ministry of Health: sulphate Hydroxychloroquine 200mgx2/day for 10 days + Azithromycin $500 \mathrm{mg}$ to $\mathrm{j} 1$ then $250 \mathrm{mg}$ /day from $\mathrm{j} 2$ to $\mathrm{j} 7$, as a management complement the patient received an antibacillary ERIP k4: 4cp/day, anticoagulant treatment based on HBPM: 0.4ui/day and symptomatic treatment. The clinical evolution was marked by apyrexia at the end of the 3rd day of treatment with progressive improvement of his respiratory symptomatology, $\mathrm{Sa} 02$ increased to $95 \%-97 \%$ in ambient air. Biologically, regular monitoring (including: NFS, liver balance, blood count, CRP, LDH, ferritin) showed a decrease in inflammatory syndrome and normalization of lymphocytes at $1300 \mu \mathrm{L}$ (Table 1). No clinical or biological side effects to treatment were reported, the electrocardiogram control remained normal throughout the treatment.

Table-1: The biological characteristics of the case

\begin{tabular}{|c|c|c|c|c|c|}
\hline Variables & Admission & Control j2 & Control j5 & Control j7 & Control j10 \\
\hline Leukocytes $(/ \mu \mathrm{L})$ & 5440 & 6380 & 6230 & 5900 & 7810 \\
\hline $\mathrm{PNN}(/ \mu \mathrm{l})$ & 4040 & 4640 & 3930 & 3700 & 4640 \\
\hline Lymphocyte $(/ \mu 1)$ & 790 & 780 & 990 & 1020 & 1300 \\
\hline Eosinophilia $(/ \mu \mathrm{l})$ & 0 & 20 & 70 & 66 & 110 \\
\hline Hemoglobin $(\mathrm{g} / \mathrm{dl})$ & 14 & 13.4 & 13.7 & 13.5 & 13.2 \\
\hline Platelets $(/ \mu \mathrm{l})$ & 278,000 & 248,000 & 226,000 & 289,000 & 317,000 \\
\hline ASAT (UI/L) & 42 & 41 & 41 & 40 & 46 \\
\hline bilirubin $(\mathrm{mg} / \mathrm{dL})$ & 4 & - & 5 & - & - \\
\hline ALAT (UI/L) & 55 & 52 & 53 & 50 & 49 \\
\hline Alkaline phosphatase (IU/L) & 66 & - & 67 & - & 66 \\
\hline Total protein $(\mathrm{g} / \mathrm{dL})$ & 61 & 57 & 59 & 55 & 62 \\
\hline Creatinine $(\mathrm{mg} / \mathrm{dL})$ & 9 & 8.6 & 9.6 & 8.4 & 7.2 \\
\hline Troponin & 0.001 & - & - & - & - \\
\hline $\mathrm{LDH}$ & 402 & - & 450 & - & 320 \\
\hline Fibrinogen $(\mathrm{g} / \mathrm{l})$ & 7.7 & - & - & - & 7.3 \\
\hline TP $\%$ & 97 & - & - & - & - \\
\hline D-dimer $(\mu \mathrm{g} / \mathrm{ml})$ & 8000 & - & - & - & - \\
\hline Ferritin (ng/dl) & 1390 & - & 1260 & - & 700 \\
\hline Glucose (mg/dL) & 0.98 & 0.70 & 0.90 & 1.01 & 0.96 \\
\hline Sodium $(\mathrm{mEq} / \mathrm{l})$ & 131 & 133 & 135 & 134 & 139 \\
\hline Potassium $(\mathrm{mEq} / \mathrm{l})$ & 4.5 & 4.4 & 4.9 & 4.6 & 5.1 \\
\hline Alkaline reserve $(\mathrm{mEq} / \mathrm{l})$ & 21 & 22 & 24 & 26 & 25 \\
\hline HIV serology & \multicolumn{5}{|c|}{ Negative } \\
\hline C-protein reactive $(\mathrm{mg} / \mathrm{dL})$ & 70 & - & 53 & & 33 \\
\hline
\end{tabular}

A PCR test for Sars-CoV-2 is performed in our patient at $\mathrm{j} 9$ and $\mathrm{j} 10$ returning negative, thus declaring the patient cured of COVID-19. After leaving the hospital, the patient is referred to the Center for Diagnosis of Tuberculosis and Respiratory Diseases (CDTMR) for additional therapeutic management of his tuberculosis.

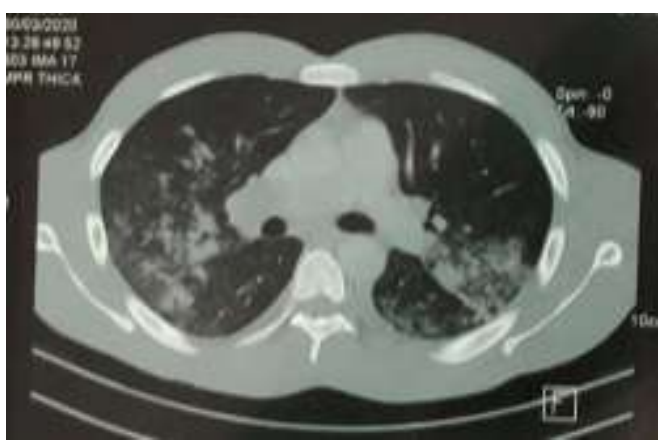

A: A parenchymal cut of a thoracic scanner, objecting to nodular bilateral opacities sometimes excavated

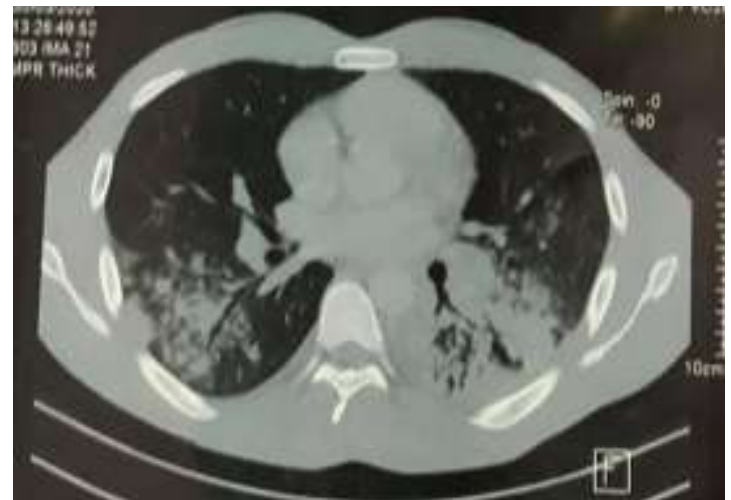

b: A parenchymal slice of a thoracic scanner, objectivant parenchymal left basal condensation with aerial bronchogram 


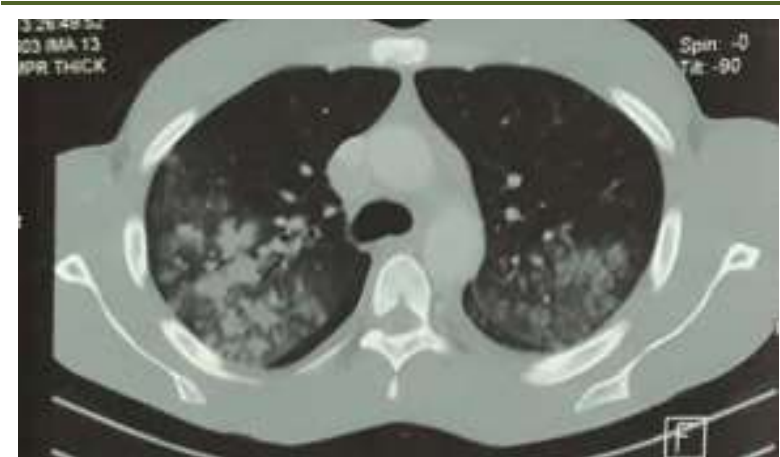

C: A parenchymal section of a thoracic scanner, objectivant bilateral nodular opacities with basal frosted glass peripheral

Image-1: Parenchymal sections of a thoracic scanner, a: bilateral nodular opacities sometimes excavated, b: left basal parenchymal condensation with aerial bronchogram c: bilateral nodular opacities with peripheral basal frosted glass

\section{DISCUSSION}

The current world is facing two health challenges, tuberculosis and COVID-19. Tuberculosis (TB) is caused by a bacterium, Mycobacterium tuberculosis, discovered in 1882 by Dr Robert Koch, and according to the WHO (4) is one of the top 10 causes of death worldwide. In Morocco tuberculosis is a major public health problem where the incidence was 86-91/100,000 inhabitants between 2006-2016 with a mortality rate of 9.3 per 100,000 inhabitants in 2016 [5].

The SARS-COV2-induced COVID-19 pandemic emerged earlier this year, with WHO officially recognizing the pandemic on March 11, 2020 [3]. As of June 12, 2020, COVID-19 has affected more than $7,410,510$ million people worldwide, resulting in more than 418,294 deaths, according to WHO [6].

Although the impact of COVID-19 on tuberculosis (TB) is not yet known, literature [4] has shown that some viral infections, including SARS-
CoV-2, cause a temporary immunosuppressant effect, inducing activation of latent bacterial infections, Thus a group of scientists have assumed in one study (1) that COVID-19 could lead to lung inflammation and that this leads to the return to service of latent tuberculosis in the lung.

Both diseases primarily attack the lungs and although both pathogens are transmitted primarily through close contact. Human-to-human transmission of SARS-CoV-2 is primarily caused by the emission of respiratory droplets loaded with viral particles. The latter could infect a susceptible subject either by direct contact with a mucous membrane (direct transmission) or by contact with a surface infected by secretions from the nasal, oral or conjunctival mucous membranes (indirect transmission) [7].

The incubation period in TB is longer, lasting several weeks or more, while symptoms of COVID-19 appear a few days after exposure to the virus. In the 1,099-patient study by Guan et al. [8], the median incubation time for SARS-CoV-2 was estimated to be 4 days While Qun et al. [9], it was estimated to be 5.2 days (4.1-7) and for $95 \%$ of patients, symptoms occurred within 12.5 days of infection. In our patient the incubation time was estimated to be seven days.

The severity of COVID-19 can vary from asymptomatic to acute respiratory distress syndrome (ARDS). According to the literature $[10,11]$ the rate of asymptomatic patients is between (17\%-29\%), while ARDS may be associated with several risk factors whose age greater than 50 years appeared as a strongly associated factor [12] also diabetes, hypertension, morbid obesity and heart disease [12-14]. On the other hand, the existence of chronic obstructive pulmonary disease (COPD), prior immunosuppression, cancerous pathology or chronic renal failure did not appear to increase the risk of mortality (table) $[9,12,14]$.

Table-2: Comorbidities associated with symptomatic SARS-CoV-2 infection

\begin{tabular}{|c|l|l|l|}
\hline Comorbidities & Guan $(\mathbf{n}=\mathbf{1 0 9 9})(\mathbf{9})$ & $\mathbf{W u}(\mathbf{n}=\mathbf{2 0 1}) \mathbf{( 1 2})$ & Zhou (n = 191) (14) \\
\hline Age (median) and IQR & $47[35-58]$ & $51[43-60]$ & $56[46-67]$ \\
\hline Age (median) and IQR & $47[35-58]$ & $51[43-60]$ & $56[46-67]$ \\
\hline Sex-ratio (M/F) & 1.4 & 1.8 & 1.7 \\
\hline Prior exposure & $43.9 \%$ & $49.3 \%$ & $38 \%$ \\
\hline Comorbidity 1 & $23.7 \%$ & $38.2 \%$ & $48 \%$ \\
\hline Active smoking & $12.6 \%$ & $\mathrm{ND}$ & $6 \%$ \\
\hline HTA & $15.00 \%$ & $19.4 \%$ & $30 \%$ \\
\hline Diabetes & $7.4 \%$ & $10.9 \%$ & $19 \%$ \\
\hline Coronary artery disease & $2.5 \%$ & $<4 \%$ & $8 \%$ \\
\hline OCAP & $1.1 \%$ & $<2.5 \%$ & $3 \%$ \\
\hline Cancer & $0.9 \%$ & $0.5 \%$ & $1 \%$ \\
\hline KPI & $0.7 \%$ & $1 \%$ & $1 \%$ \\
\hline
\end{tabular}

IQR: inter quartile interval; M/F: men/women; Hypertension: high blood pressure; COPD: obstructive bronchopneumopathy; CKD chronic kidney failure; ARDS: acute respiratory distress syndrome 
People with COVID-19 and those with TB have a rich clinical picture that is essentially respiratory. SARS-CoV-2 infection occurs clinically based on the three studies of Wu et al., Guan et al. and Zhou et al. [9,12,14], cardinal signs of COVID-19 associated with fever above $37.5 \mathrm{C}(88.7-4 \%)$, cough (67.8-81.1\%), sputum (23-41.3\%) and dyspnea (18.7$39.8 \%$ ), occurring in the early days of infection. A cohort study (15) recruited by the Global Tuberculosis Network (GTN) in 8 countries and 3 continents involving 49 TB patients with or after-effects of COVID-19, in the 42 active TB cases, symptoms of COVID-1919 appeared inconstant: $81.2 \%$ fever, 56.2\% cough, $35.4 \%$ dyspnea. Our patient presented the same respiratory symptomatology accompanied by headache, anosmia, agueusie and alteration of the general state.

Radiologically, pulmonary tuberulosis occurs at chest computed tomography (CT) with very diverse parenchymal lesions, they are isolated or associated, to type of alveolar, infiltrative or cave opacities. However, the location of lesions in the upper lobes remains evocative [16]. As for COVID-19 the radiological signs are little specific, the table was that of pneumopathy often bilateral in $95.2 \%$ with abnormalities with posterior distribution and sub-pleural, combining frosted glass images, pockets of alveolar condensation, linear opacities, but also thickening of the bronchial walls and more rarely pleurisy and pericardial effusion [8, 17], therefore the Dutch Radiological Society (NVvR) [18] developed CO-RADS based on other classifications to assess the suspicion of lung involvement in COVID-19 on a scale of 1 (very low) to 5 (very high). CO-RADS is intended for use in patients with moderate to severe symptoms of COVID-19. In the Tadolini $\mathrm{M}$ et al. [15] study, the combination of TB and COVID19 was associated with a typical COVID-19 imaging presentation for 21 of them, while 23 were more likely to have TB-suggestive imaging. While the scannographic aspect of our patient had the peculiarity to associate the two types of parenchymal lesions.

As with our patient (Table 1), the symptomatic forms of SARS-CoV-2 infection are accompanied by multiple biological changes:

- Elevation of neutrophil polynuclear cells and lymphopenia, extended to CD4 and CD8 lymphocytes [14]

- CRP elevation (60.7-85.6\%), up to $150 \mathrm{mg} / \mathrm{L}$, hypoalbuminemia (median 32-32.3 g/L), hyperferritinemia (78.5-80\%) (12.14)

- Elevation of ALAT/ASAT in approximately $25 \%(21.7-31 \%)$ and hyperbilirubinemia (5.1$10.5 \%)(9.14)$

- Elevated LDH for approximately $40 \%$ of patients (13-98\% depending on the threshold chosen in the studies) associated with decreased PT (up to $94 \%$ of patients) and increased D-dimers (23.3-46.4\%), coagulopathy stigma associated with severe and predictive forms of mortality $[12,14]$

Tuberculosis such as COVID-19 is characterized by high levels of CRP, lymphopenia, hypoprotidemia and hypoalbuminemia, sometimes associated with anemia and thrombocytosis [19].

To date, there are no vaccines or drugs specific to COVID-19, treatments are being studied and will be tested in clinical trials. Among these on-site treatments, hydroxychloroquine, in addition to its antiviral activity, is used in autoimmune diseases for its immunomodulation capabilities. This is mediated by its activity of inhibition of the signaling of TLR7 and 9, leading to the decrease of IFN-I secretion [20], but also regulation of $\mathrm{T}$ lymphocytic activation $[21,22]$ and the secretion of inflammatory cytokines [23]. In vitro studies of COVID-19-causing coronavirus strains support the potential antiviral interest of chloroquine Wang et al., [24] and hydroxychloroquine Yao et al., [25]. The results of a recent in vitro assay showed a synergistic effect of the combination of hydroxychloroquine and azithromycin on the reduction of replication of SARS-CoV-2 at concentrations consistent with those that can be obtained at the pulmonary level in humans [26]. In the cohort study [27] with 3,737 cases of SARS-CoV-2, placed under the "hydroxychloroquine-azithromycin" protocol, there was a decrease in the risk of transfer to intensive care or death (HR $0.190 .12-0.29$ ), with a decrease in the risk of hospitalization 10 days (odds ratios IC 95\% 0.370 .26 0.51 ) and a shorter duration of viral excretion (time before negative PCR: HR 1.27 1.16-1.39). Several recommendations exist on the management of thrombotic risk during SARS-CoV-2 infection [28] all agree to recommend heparin-based thromboprophylaxis for hospitalized patients. There is a debate about the preventive dose of heparin to be taken, with some teams prescribing intermediate doses to prevent the thrombotic events we have just described [29]. With regard to viral clearance, it was estimated according to the study of Wang L et al. [30] at 19.5 days (17-24 days), for Young B et al. at 12 days (1-24 days) while the cure that is to say absence of symptoms, PCR negative, was at 10 days (3-15 days) according to $[30,31]$. In the absence of a clear and specific recommendation for TB and COVID-19 co-infection, our patient was treated with the combination of hydroxychloroquine- azithromycin, an anticoagulant treatment with a preventive dose and antibacillary treatment, with fairly satisfactory results, the PCR at SARS-CoV-2 came back negative after 09 days of treatment.

COVID-19 is associated with a high mortality rate that remains variable by country (32.33). A metaanalysis [32] of 10 studies included, 50,466 patients, resulted in a $4.7 \%$ mortality rate, in Morocco this rate is around $3.7 \%$ (official website of the Moroccan Ministry 
of Health). Furthermore, the prognosis of TB and COVID-19 co-infection remains unknown, in the series of Tadolini $\mathrm{M}$ et al. [15], six required non-invasive ventilation and 14 oxygen therapy, while six died, 5 of whom were over 60 years old. All with at least one associated comorbidity. However, our patient had the particularity of having a favorable clinical and biological evolution.

\section{CONCLUSION}

Given that a quarter of the world's population has latent TB and given the rapid spread of the COVID19 pandemic, broader studies are needed to study the prognosis of this association and to understand any role played by SARS-CoV-2 in the progression of TB infection and possibly open up new perspectives for research and therapeutic innovations.

\section{REFERENCE}

1. Pathak L, Gayan S, Pal B, Talukdar J, Bhuyan S, Sandhya S, Yeger H, Baishya D, Das B. Coronavirus activates a stem cell-mediated defense mechanism that reactivates dormant tuberculosis: implications in COVID-19 pandemic. bioRxiv. 2020 Jan 1.

2. Wu Y, Ho W, Huang Y, Jin DY, Li S, Liu SL, Liu X, Qiu J, Sang Y, Wang Q, Yuen KY. SARS-CoV2 is an appropriate name for the new coronavirus. The Lancet. 2020 Mar 21;395(10228):949-50.

3. World Health Organization. World Health Organization (WHO) Information Note Tuberculosis and COVID-19.

4. Global Tuberculosis Report. 2019

5. Tuberculosis control guide for health professionals Version. 2017.

6. https://www.who.int/en

7. Van Doremalen N, Bushmaker T, Morris DH, Holbrook MG, Gamble A, Williamson BN, Tamin A, Harcourt JL, Thornburg NJ, Gerber SI, LloydSmith JO. Aerosol and surface stability of SARSCoV-2 as compared with SARS-CoV-1. New England Journal of Medicine. 2020 Apr 16;382(16):1564-7.

8. Li Q, Guan X, Wu P, Wang X, Zhou L, Tong Y, Ren R, Leung KS, Lau EH, Wong JY, Xing X. Early transmission dynamics in Wuhan, China, of novel coronavirus-infected pneumonia. New England Journal of Medicine. 2020 Jan 29.

9. Guan WJ, Ni ZY, Hu Y, Liang WH, Ou CQ, He JX, Liu L, Shan H, Lei CL, Hui DS, Du B. Clinical characteristics of coronavirus disease 2019 in China. New England journal of medicine. $2020 \mathrm{Apr}$ 30;382(18):1708-20.

10. Mizumoto K, Kagaya K, Zarebski A, Chowell G. Estimating the asymptomatic proportion of coronavirus disease 2019 (COVID-19) cases on board the Diamond Princess cruise ship, Yokohama, Japan, 2020. Euro Surveill. 2020;25(10):2000180.
11. Hu Z, Song C, Xu C, Jin G, Chen Y, Xu X. Clinical characteristics of 24 symptomatic infections with COVID-19 screened among close contacts in Nanjing, China. Sci China Life Sci. 2020:10,

12. Wu C, Chen X, Cai Y, Xia J, Zhou X, Xu S. Risk factors associated with acute respiratory distress syndrome and death in patients with coronavirus disease 2019 pneumonia in Wuhan, China. JAMA Intern Med. 2020: e200994,

13. Sentinel Network, France. https://websenti.u707.jussieu.fr/sentiweb/Consulté. April 12, 2020.

14. Zhou F, Yu T, Du R, Fan G, Liu Y, Liu Z. Clinical course and risk factors for mortality of adult in patients with COVID-19 in Wuhan, China: a retrospective cohort study. Lancet. 2020; 395(10229):1054-62.

15. Mizumoto K, Kagaya K, Zarebski A, Chowell G. Estimating the asymptomatic proportion of coronavirus disease 2019 (COVID-19) cases on board the Diamond Princess cruise ship, Yokohama, Japan, 2020. Eurosurveillance. 2020 Mar 12;25(10):2000180.

16. Kamamfu G, Nikoyagize E, Ndayirgije A, Mucikire E, Nzeyimana H, Aubry P. Radiological aspects of pulmonary tuberculosis associated with human immunodeficiency virus (HIV) infection. Med Afrique Noire. 1990; 37: 594-7.

17. Zu ZY, Jiang MD, Xu PP, Chen W, Ni QQ, Lu GM, Zhang LJ. Coronavirus disease 2019 (COVID-19): a perspective from China. Radiology. 2020 Feb 21:200490.

18. Prokop $M$, van Everdingen W, van Rees Vellinga T, van Ufford JQ, Stöger L, Beenen L, Geurts B, Gietema H, Krdzalic J, Schaefer-Prokop C, van Ginneken B. CO-RADS-A categorical CT assessment scheme for patients with suspected COVID-19: definition and evaluation. Radiology. 2020 Apr 27.

19. Hedhli A, Racil H, Bacha S Mhiri E, Cheikhrouhou S, Chaouch N, Chabbou A. "Clinical and biological manifestations associated with extended pulmonary tuberculosis https://doi.org/10.1016/j.rmr.2015.10.260

20. Sacre K, Criswell LA, McCune JM. Hydroxychloroquine is associated with impaired interferon-alpha and tumor necrosis factor-alpha production byplasmacytoid dendritic cells in systemic lupus erythematosus. Arthritis ResTher. 2012; 14:R155.

21. Namiuchi S, Kumagai S, Imura H, Suginoshita T, Hattori T, Hirata F. Qui-nacrine inhibits the primary but not secondary proliferative response ofhuman cytotoxic $\mathrm{T}$ cells to allogeneic non-T cell antigens. J Immunol. 1984;132(3):1456-61.

22. Goldman FD, Gilman AL, Hollenback C, Kato RM, Premack BA, Rawlings DJ. Hydroxychloroquine inhibits calcium signals in $\mathrm{T}$ cells: a new mechanism toexplain its 
immunomodulatory properties. Blood. 2000;95:3460-6.

23. Picot S, Peyron F, Vuillez JP, Polack B, AmbroiseThomas P. Chloroquine inhi-bits tumor necrosis factor production by human macrophages in vitro. J Infect Dis. 1991; 164:830.

24. Wang M, Cao R, Zhang L, Yang X, Liu J, Xu M, Shi Z, Hu Z, Zhong W, Xiao G. Remdesivir and chloroquine effectively inhibit the recently emerged novel coronavirus (2019-nCoV) in vitro. Cell research. 2020 Mar;30(3):269-71.

25. Yao X, Ye F, Zhang M, Cui C, Huang B, Niu P, Liu X, Zhao L, Dong E, Song C, Zhan S. In vitro antiviral activity and projection of optimized dosing design of hydroxychloroquine for the treatment of severe acute respiratory syndrome coronavirus 2 (SARS-CoV-2). Clinical Infectious Diseases. 2020 Mar 9.

26. Andreania J, Le Bideaua M, Duflota I, Jardota P, Rollanda C, Boxbergera M, Khalila JY, Baudouinb JP, Wurtza N, Rolaina JM, Colsona P. In vitro testing of hydroxychloroquine and azithromycin on SARS-CoV-2 shows 1 synergistic effect 2 . lung. 2020;21:22.

27. Early diagnosis and management of COVID-19 patients: a real-life cohort study of 3,737 patients, Marseille, France COVID-IHU \#15 Version 1 of May 27, 2020

28. Bikdeli B, Madhavan MV, Jimenez D, Chuich T, Dreyfus I, Driggin E, Der Nigoghossian C, Ageno
W, Madjid M, Guo Y, Tang LV. COVID-19 and Thrombotic or Thromboembolic Disease: Implications for Prevention, Antithrombotic Therapy, and Follow-Up: JACC State-of-the-Art Review. Journal of the American College of Cardiology. 2020 Jun 16;75(23):2950-73.

29. Middeldorp S, Coppens M, van Haaps TF, Foppen M, Vlaar AP, Müller MC, Bouman CC, Beenen LF, Kootte RS, Heijmans J, Smits LP. Incidence of venous thromboembolism in hospitalized patients with COVID- 19. Journal of Thrombosis and Haemostasis. 2020 May 5.

30. Barnaby Edward Young, MB, BChir1,2,3; Sean Wei Xiang Ong, MBBS1,2; Shirin Kalimuddin, MPH4,5. Epidemiological characteristics and clinical evolution of SARS-CoV-2 infected patients in Singapore JAMA. 2020; 323 (15): 1488-1494. doi: 10.1001/ jama.2020.3204

31. Pan F, Ye T, Sun P, Gui S, Liang B, Li L, Zheng D, Wang J, Hesketh RL, Yang L, Zheng C. Time course of lung changes on chest CT during recovery from 2019 novel coronavirus (COVID19) pneumonia. Radiology. 2020 Feb 13:200370.

32. Sun P, Lu X, Xu C, Sun W, Pan B. Understanding of COVID- 19 based on current evidence. Journal of medical virology. 2020 Jun; 92(6):548-51.

33. Cascella M, Rajnik M, Cuomo A, Dulebohn SC, Di Napoli R. Features, evaluation and treatment coronavirus (COVID-19). InStatpearls [internet] 2020 Mar 8. Stat Pearls Publishing. 